\title{
David F. Chang (ed): Curbside Consultation in Cataract Surgery
}

\author{
Thorofare, NY: Slack Inc, 2007, 256 pp, Soft cover (ISBN: 978-1-55642-799-2)
}

\author{
Shimon Rumelt
}

Received: 11 December 2009 /Accepted: 20 December 2009/Published online: 4 February 2010

(C) Springer-Verlag 2010

This book is part of a series in different subspecialties edited by Dr. Chang, a leader in cataract surgery, who recruited prominent and pioneers in phacoemulsification. Each chapter was written by a different expert who answers a different question concerning a challenging situation in phacoemulsification. The 49 answers (one per chapter) provide the readers with an approach to solve pre-, intra- or postoperative problems, and include a background and pathophysiology. They provide practical solutions to problems and challenges occurring perioperatively that would assist the general and anterior segment surgeon. Each answer (or chapter) has references. Thus, the book title reflects its contents. This soft-cover book is vividly illustrated with both clinical and diagrammatic illustrations. It contains a table of contents, data on contributing authors and index. The style and format are adequately clear, and the book is fluently readable.

Similar titles have been published [Lu LW, Fine IH (1999) Phacoemulsification in difficult and challenging cases. Thieme, New York; and Buratto L, Osher R, Masket

S. Rumelt $(\square)$

Department of Ophthalmology, Western Galilee-Nahariya

Medical Center,

Nahariya, Israel

e-mail: shimon.rumelt@naharia.health.gov.il
S (2000) Cataract surgery in complicated cases. Slack Inc., Thorofare, NY], without having chapter titles as questions, but as time elapses, more challenges are encountered and new solutions are found. Albeit, the topics do not cover all the challenging situations in cataract surgery like mature rock-hard (brown, red and black) cataracts, phaco in vitrectomized eyes with or without zonular support, differentiation between toxic anterior chamber and endophthalmitis, their prevention and management, as well as other topics. Some of these topics have been addressed by other publications. Hopefully, more issues will be included in forthcoming editions. It would be interested to know how different surgeons approach the same challenge because several approaches may be employed to solve the same problem. For example, the answer for Question 17 mentioned only one method for retrieving radial capsular tear, and without describing how to handle a tear that extended beyond the zonules and into the equator. Another answer to Question 46 supports the employment of different types of intraocular lenses in the fellow eye; claiming that patients can neuro-adapt is still under debate. Adjoining multiple experts to give their own perspectives on the same question may be a subject for a new title.

Overall, this is a practical concise guidebook for the cataract surgeon facing perioperative challenges and complications. 